\title{
Hallazgo del mosquito Haemagogus equinus (Theobald, 1903) en el área metropolitana de Bucaramanga, Santander
}

\author{
Víctor A. Olano ${ }^{1}$, Adriana Bueno ${ }^{2}$, Claudia J. González ${ }^{1}$, María C. Correa ${ }^{3}$
}

\begin{abstract}
Resumen
Utilizando un sistema de vigilancia entomológica, se registra por primera vez en Colombia el hallazgo del mosquito Haemagogus equinus, eficiente vector del virus de la fiebre amarilla selvática, en criaderos artificiales (llantas). Se recolectaron 181 larvas de $H$. equinus en cuatro ovilarvitrampas encontradas positivas, localizadas en el área metropolitana de Bucaramanga.
\end{abstract}

\section{Summary}

Using an entomological surveillance system, the presence of the mosquito Haemagogus equinus has been registered for the first time in Colombia. It is an eficient vector of forest yellow fever virus in artificial containers (tires). $181 \mathrm{H}$. equinus larvae were collected in 4 egg-larvae traps, located in the metropolitan area of Bucaramanga, and found to be positive.

Haemagogugs equinus (Theobald, 1903) (Diptera: Culicidae) es un mosquito de distribución neotropical. Ha sido hallado en todos los países centroamericanos, en algunas regiones antillanas como Jamaica, en Estados Unidos y se presume que se encuentra en territorio neártico; en Suramérica, se encuentra en Colombia, Venezuela, Trinidad, Tobago y Guayanas (1). En Colombia, ha sido registrado en los departamentos de Antioquia, Cesar, Córdoba, Cundinamarca, La Guajira, Huila, Magdalena, Santander, Tolima y Meta entre los 2 y $1.007 \mathrm{msnm}(2,3)$.

Es una especie silvestre que se localiza especialmente en la copa de los árboles, con hábitos de picadura diurnos. Para el desarrollo de sus larvas, utiliza apreciable variedad de hábitats como huecos de árbol, axilas de hojas, troncos cortados de bambú y huecos de rocas en áreas de bosque húmedo tropical (bh-T), bosque seco tropical (bs-T) y subtropical (bs-ST), bosque húmedo premontano (bh-PM) y monte espinoso subtropical (me-ST). Sus larvas también se han encontrado en áreas rurales en Calabacito y Villanueva (La Guajira); en la zona urbana de Fonseca (La Guajira), Guaduas (Cundinamarca) y Ortega (Tolima) en hueco de árbol, junto con larvas de Aedes aegypti $(2,4)$. Se trata de una especie de rápida eclosión y desarrollo, lo que explica sus altas densidades después de un período de lluvias (1).

Haemagogus equinus ha sido encontrado albergando virus de fiebre amarilla en condiciones naturales. En 1957, Rodaniche y Galindo (5) aislaron el virus por primera vez para Centroamérica en Matagua, Guatemala. En Colombia, se ha hallado $H$. equinus infectado en condiciones naturales (6).

La fiebre amarilla es debida a un arbovirus (familia: Togaviridae; orden: Flavivirus), la cual presenta una alta letalidad (60-70\%), esporádica o epidémica en el hombre, enzooepizoótica en algunos mamíferos selváticos, principalmente los monos

${ }^{1}$ Labcratorio de Entomología, Instituto Nacional de Salud, Santa Fe de Bogotá

${ }^{2}$ Secretaría del Medio Ambiente, Alcaldía de Bucaramanga, Santander.

${ }^{3}$ Secretaría de Salud de Santander, Bucaramanga. 
(Alouatta seniculus) que constituyen los reservorios habituales del virus, aunque también en marsupiales y posiblemente roedores. Esta patología presenta dos formas epidemiológicas: la urbana, en la cual el transmisor es el Aedes aegyptiy el hombre es el hospedero y la selvática, donde los reservorios primordiales son los monos y los transmisores mosquitos del género Haemagogus (7) y algunos del género Sabethes (4).

En el interior del país es donde la forma selvática adquiere mayor interés y nos muestra cómo esta modalidad, en su forma original y primitiva, ocurre en nuestra selvas en donde abundan los reservorios. Esto ha sucedido en regiones como Muzo, las selvas del Magdalena medio que dieron origen a las epidemias del alto Magdalena en el oriente colombiano, especialmente en Santander y Norte de Santander, en municipios como San Vicente de Chucurí, Bucaramanga, Ocaña y Cúcuta, entre otros, donde más casos se han presentado desde 1910; además, el piedemonte de la cordillera oriental desde Putumayo hasta los límites con Venezuela (8). En San Vicente de Chucurí, entre 1936 y 1959 , se diagnosticaron 81 casos humanos de esta enfermedad (9).

La reurbanización de la fiebre amarilla en el área metropolitana de Bucaramanga, donde hay presencia de Aedes aegypti, se constituye en un riesgo, teniendo en cuenta los brotes epidémicos de fiebre amarilla urbana ocurridos en Bucaramanga entre 1910 y 1923 y que la última edpidemia urbana registrada en el país ocurrió en El Socorro en 1929 y en las cercanías de Santa Helena del Opón, zona endémica actual de fiebre amarilla selvática y de San Vicente de Chucurí (distante $86 \mathrm{~km}$ de la capital santandereana), con antecedentes epidémicos de esta patología.

Bajo condiciones de laboratorio, Hayes y colaboradores (10) demostraron, con pruebas satisfactorias, la susceptibilidad de $H$. equinus a la transmisión del virus de la encefalitis equina de San Luis (ESL) y de Souza (11), en el mismo año, también demostró, por inoculación intratoráxica, la transmición vertical del dengue tipo 1 en Panamá, lo que hace al $H$. equinus un vector potencial con mayor rango de transmisión de patologías al hombre.
El objetivo de este documento es registrar, por primera vez para Colombia, la presencia de larvas de $H$. equinus en hábitats artificiales (llantas) en el aeropuerto Palonegro, el Jardín Botánico, el Hospital San Juan de Girón y el cementerio Las Colinas en Bucaramanga, lo cual demuestra su desplazamiento al ambiente humano, constituyéndose en peligro potencial la domesticación de sus sitios de cría.

\section{Metodología}

A raíz del informe de julio de1997 de la Fundación Nacional de Salud del Brasil sobre el hallazgo de Aedes albopictus en la ciudad de Tabatinga en la frontera con Leticia, capital del departamento del Amazonas, el Ministerio de Salud envió en agosto del mismo año, una circular a todos los directores seccionales y distritales de salud, mediante la cual debería intensificarse en el país la vigilancia del Aedes albopictus eficiente vector del virus del dengue y vector potencial de la fiebre amarilla, la encefalitis equina venezolana y la encefalitis equina del Este, con el objeto de evitar la introducción de esta especie al país.

La Secretaría del Medio Ambiente de la alcaldía de Bucaramanga y la Secretaría de Salud de Santander con base en la advertencia de la OPS sobre la vigilancia de este mosquito, difundida en la circular No. 019 del 16 de septiembre de 1993 del Ministerio de Salud, había establecido un sistema de vigilancia entomológica en Bucaramanga y su área metropolitana, a partir de 1994, utilizando ovilarvitrampas (Ilantas de automóvil con agua), las cuales se ubicaron a una altura de $1 \mathrm{~m}$ sobre el nivel del suelo (OPS, 1993) (figura 1).

Para la realización de la vigilancia entomológica, se escogieron nueve sitios para la localización de las ovilarvitrampas en el área metropolitana de Bucaramanga teniendo como criterio los puntos de entrada de pasajeros y carga a la ciudad, zonas boscosas y el área de reencauche de llantas (cuadro 1).

Se realizaron inspecciones semanales y el material inmaduro recolectado se empacó en cárpulas con alcohol al $70 \%$, debidamente etiquetadas. La identificación a nivel de especie 


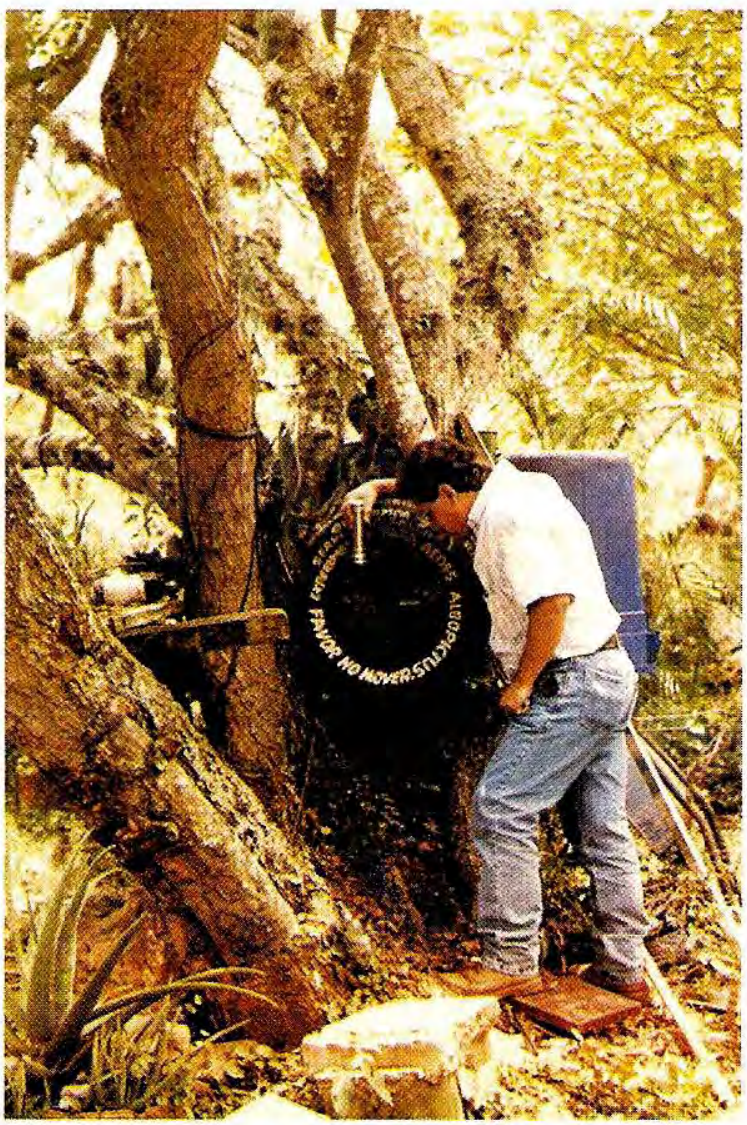

Figura 1. Llanta de automóvil con agua utilizada como ovilarvitrampa para A. albopictus.

Cuadro 1. Sitios de localización de las ovilarvitrampas.

\begin{tabular}{|c|c|c|}
\hline Trampa & Sitio & Descripción \\
\hline 1 & Aeropuerto Internacional Palonegro & $\begin{array}{l}\text { A } 100 \mathrm{~m} \text { de la zona de carga y descarga de } \\
\text { aviones }\end{array}$ \\
\hline 2 & Centroabastos & $\begin{array}{l}\text { Ingreso de abarrotes, ubicada en zona boscosa a } \\
20 \mathrm{~m} \text { de las bodegas. }\end{array}$ \\
\hline 3 & Terminal de transporte intermunicipal & En zona de acceso de los pasajeros a los buses. \\
\hline 4 & Icollantas & $\begin{array}{l}\text { En la bodega central, almacenaje de llantas para } \\
\text { reencauche. }\end{array}$ \\
\hline 5 & Jardin Botánico Eloy Valenzuela & $\begin{array}{l}\text { Se dió cobertura a todo el jardín de } \\
\text { aproximadamente } 2 \text { hectáreas de bosque tropical } \\
\text { (se ubicaron } 6 \text { trampas). }\end{array}$ \\
\hline 6 & Hotel San Juan de Girón & $\begin{array}{l}\text { En zona boscosa; puerta de entrada a } \\
\text { Bucaramanga por la vía del Magdalena medio. }\end{array}$ \\
\hline 7 & Asilo San Rafael & $\begin{array}{l}\text { Zona urbana; acceso a la ciudad de pasajeros y } \\
\text { carga proveniente de la costa norte. }\end{array}$ \\
\hline 8 & Parque cementerio La Colina & Area boscosa; distante $300 \mathrm{~m}$ del Campo Santo. \\
\hline 9 & Zona Industrial & Area circundada por vegetación. \\
\hline
\end{tabular}

se hizo utilizando las claves de Tinker (12), Lane (13), Forattini (1) y Kumm (6), especializadas en la familia Culicidae del neotrópico.

\section{Resultados}

Hasta marzo de 1997, no se había encontrado ninguna trampa positiva para Aedes albopictus, pero, como resultado indirecto de esta vigilancia, se detectó por primera vez en Bucaramanga y su área metropolitana en cuatro ovilarvitrampas (cementerio Las Colinas, aeropuerto Palonegro, Hotel San Juan de Girón y Jardín Botánico) el mosquito Haemagogus equinus, vector eficiente en Colombia de la fiebre amarilla selvática (Kumm et al.,1946; Morales et al.,1984). Se recolectó un total de 181 larvas de $H$. equinus.

En Tobago (West Indies), en un estudio de vigilancia de Aedes aegypti realizado entre 1983 y 1988 , de un total de 10.444 ovilarvitrampas expuestas (miscelánea de contenedores), que no incluían llantas, se encontraron 158 (4.747) de $H$. equinus (14).

Este hallazgo se constituye en el primer informe para el país sobre el desarrollo de Haemagogus equinus en criaderos artificiales (llantas).

La utilidad de un sistema de vigilancia entomológica radica en mantener actualizada la información sobre la presencia, distribución y dispersión de las especies de mosquitos vectores 
de patologías al hombre, así como para detectar a tiempo la introducción de especies no nativas e identificar situaciones de riesgo para seleccionar las medidas adecuadas de control vectorial en epidemias, como también para evaluar las intervenciones realizadas.

\section{Referencias}

1. Forattini O. Entomología Médica. Vol. III. Sao Paulo: Universidade de Sao Paulo; 1965.

2. Morales A. Distribución geográfica, horizontal y vertical de Haemagogus (Diptera: Culicidae) de Colombia. Rev Acad Cien Fis Exac y Nat 1968;13 (50):267-72.

3. INS. Subdirección de Epidemiología y Laboratorio Nacional de Referencia, Laboratorio de Entomología Datos sin publicar, 1997.

4. Morales A, Ferro MC, Isaza C, Cura E. Búsqueda de mosquitos del género Haemagogus en el departamento de La Guajira, Colombia, S. A. (Diptera: Culicidae). Biomédica 1984;4(1):25-6.

5. Rodaniche E, Galindo P. Isolation of yellow fever virus from Haemagogus mesodentatus, $H$. equinus y Sabethes chloropterus captured in Guatemala in 1956. Am J Trop Med 1957;8(6):232-7.
6. Kumm H, Osorno E, Boshell J. Studies on mosquitoes of the genus Haemagogus in Colombia (Diptera: Culicidae). Am J Hyg 1946;43:13-28.

7. Halbrorh J. Fiebre amarilla en Venezuela. Rev Inst Nal Hig 1985;18(3-4):47-65.

8. Gast Galvis A. Historia de la fiebre amarilla en Colombia. Bogotá: Instituto Nacional de Salud; 1982.

9. Groot H, Morales A, Vidales $\mathbf{H}$. Virus isolations from forest mosquitoes in San Vicente de Chucurí, Colombia. Am J Trop Med 1961;10(3):397-402.

10. Hayes C, Duraty B, Reeves WC, Adames AJ, Galindo P. Experimental studies to determine the susceptibility to infection with St. Louis virus of five species of Panamanian mosquitoes. J Am Mosq Cont Assoc 1991;7(4):584-7.

11. de Souza M, Freier JE. Vertical transmission of dengue 1 virus by Haemagogus equinus mosquitoes. J Am Mosq Cont Assoc 1991;7(1):118-20.

12. Tinker ME. Clave práctica para los mosquitos de recipientes en Colombia, documento;1981:1-6.

13. Lane J. Neotropical Culicidae. Sao Paulo: Universidade de Sao Paulo; 1953, Vol. II.

14. Chadde D. Aedes aegypti surveillance in Tobago, West Indies (1983-1988). J Am Mosq Contr Assoc 1990;6(1):148-50. 